\title{
Dye Regeneration Kinetics of Sensitized Nickel Oxide Films under Illumination Investigated by Scanning Electrochemical Microscopy
}

\author{
Anshebo Getachew Alemu1, Teketel Alemu² \\ ${ }^{1}$ Department of Physics, Faculty of Natural and Computational Science, Samara University, Samara, Ethiopia \\ ${ }^{2}$ Department of Chemical Engineering, Faculty of Engineering, Adama Science and Technology University, Adama, Ethiopia \\ Email: agetachew2013alem@yahoo.com, teketela20@gmial.com
}

How to cite this paper: Alemu, A.G. and Alemu, T. (2021) Dye Regeneration Kinetics of Sensitized Nickel Oxide Films under Illumination Investigated by Scanning Electrochemical Microscopy. Advances in Materials Physics and Chemistry, 11, 78-92. https://doi.org/10.4236/ampc.2021.114008

Received: December 29, 2020

Accepted: April 9, 2021

Published: April 12, 2021

Copyright $\odot 2021$ by author(s) and Scientific Research Publishing Inc. This work is licensed under the Creative Commons Attribution International License (CC BY 4.0).

http://creativecommons.org/licenses/by/4.0/

\begin{abstract}
Scanning electrochemical microscopy (SECM) feedback mode has been used to investigate regeneration kinetics on P1 (4-(bis-\{4-[5-(2,2-dicyanovinyl) thiophene-2-yl] pH-enyl $\}$ amino) benzoic acid) dye sensitized nickel oxide $(\mathrm{NiO})$ electrodes in contact with reduced iodide liquid electrolyte in different electrolyte solvents. We were used acetonitrile, ethanol, methanol and propylene carbonate solvents for comparison under illumination of different wavelengths. We found significant variation of regeneration kinetics parameters such as regeneration rate constant $\left(k_{\text {eff }}\right)$, the reduction rate constant $\left(k_{\text {red }}\right)$ and absorption cross-section ( $\Phi \mathrm{hv})$ in different illumination intensity and different solvents.
\end{abstract}

\section{Keywords}

Scanning Electrochemical Microscopy, Nickel Oxide, Regeneration Kinetics

\section{Introduction}

Over the past decades, dye-sensitized solar cells (DSSCs) emerged as a new innovative technology for development of environmentally clean and low-cost energy source. Dye sensitized solar cells (DSSCs) provide a technically trustworthy alternative concept for p-n junction photovoltaic devices [1] [2] [3]. Efficient charge separation in DSSCs is achieved by photo induced electron injection from light absorbing sanitizer into the conduction band of nanocrystalline electrode [4]. Dye sensitized solar cells composed of mesoporous nanocrystalline films modified sensitizing dyes as photo electrodes, electrolytes and counter electrodes [5]. In past decades, the enormous attention has been given on $n$-type 
based DSSCs ( $\mathrm{TiO}_{2}$ or $\mathrm{ZnO}$ nanoparticles based solar cells) [6]; relatively few works have been reported on sensitization of p-type semiconductors DSSCs [7] [8]. More recently, dye sensitization p-type semiconductors with mesoporous, $\mathrm{NiO}$-based protective electrode get much interest research due to the development of new materials. Dye sensitization of the p-type semiconductors happens with a hole injection mechanism, from the illumination excited dye to the semiconductor. The reported efficiency for p-type DSSCs is significantly lower than n-type DSSCs solar cell [9] [10] [11] [12]. We used the p-type semiconductor $\mathrm{NiO}$, which has a band gap of $\sim 3.5 \mathrm{eV}$ and has the advantage of stability and transparency. But the efficiency of P-type semiconductor not based DSSCs is still low due to a number of reasons, such as the low potential difference, insufficient driving force, fast charge recombination between reduced dye and holes in p-type semiconductors.

Upon light absorption of the dye, the frequency of the charge-transfer reaction of the photo chemically reduced dye molecules to the electrolyte must be competitive with the tremendously fast charge recombination process between the reduced dye molecules and injected holes in the $\mathrm{NiO}$ electrode. Dye regeneration reaction to P-type dye sensitized solar cells the reaction of the excited dye reduced form with one iodide ion that might lead to the formation of an intermediate complex. The dye regeneration kinetics, process significantly affected by electrolyte solvent, dye solvent and dye concentration and dye loading time [13] [14] [15]. In past decades, investigation of dye regeneration on DSSCs has been performed by spectroscopy, photo electrochemistry characterization of individual electrode and by nanosecond transient absorption spectroscopy (TAS), which provides valuable information about the regeneration of sensitized solar cells [16] [17] [18]. In this study, we used SECM approach curve measurement to investigate kinetics of dye regeneration. We explore the effects solvent on the regeneration kinetics of P1 dye (molecular structure as shown in Figure 1(a)) with reduced iodide electrolyte $(I)$ in different illumination in different electrolyte solvents, such as acetonitrile, methanol, ethanol and propylene carbonate respectively.

\section{Experimental Section}

\subsection{Preparation of the P1/NiO Film}

The $\mathrm{NiO}$ paste was prepared as fellow $4 \mathrm{gm}$ of $\mathrm{NiO}$ nanoparticles (particle size $\sim 20 \mathrm{~nm}$ ), were ball-milled in $50 \mathrm{~mL}$ ethanol overnight. The mixture of above colloidal solution, $4.4 \mathrm{gm} \mathrm{EC} \mathrm{(30} \mathrm{-} 60 \mathrm{mPas})$ and $5.6 \mathrm{gm} \mathrm{EC} \mathrm{(5} \mathrm{-} 15 \mathrm{mPa})$ ethyl cellulose and $10 \mathrm{gm}$ triponal were sonicated and stirred overnight alternatively to obtain a fine dispersion. A paste was made by evaporating the ethanol from the mixture on a rotary evaporator. FTO glass were coated with nickel acetate ethanol solution $(0.05 \mathrm{M})$ by dip-coating and subsequently dried before screen print. The photocathode films were screen-printed with the $\mathrm{NiO}$ paste and dried for $5 \mathrm{~min}$ at $125^{\circ} \mathrm{C}$ [19] [20] [21]. 


\subsection{SECM Apparatus and Procedure}

SECM apparatus for dye sensitized solar experiments is described elsewhere [22]. SECM experiments were performed on the CHI920C electrochemical workstation ( $\mathrm{CH}$ Instruments, Shanghai). A homemade Teflon cell with a volume of $2 \mathrm{ml}$ was used to hold a pot wire counter electrode, an $\mathrm{Ag} / \mathrm{Ag}^{+}$reference electrode. The dye sensitized $\mathrm{NiO}$ film coded as no/P1 electrodes were placed at the bottom sealed with an $\mathrm{O}$ ring. An extra PT wire connected the back contact of the $\mathrm{NiO} / \mathrm{P} 1$ sample with reduced $(I)$ electrolyte to operate the photo electrochemical cell in a short-circuit setup. The LEDs were placed close to the dye coated sample on the back side and focused on film electrodes by an objective lens incident light power on the illuminated area $0.0785 \mathrm{~cm}^{2}$ and photon flux density $J_{h V}$ of $J_{h V}$ of $2.2 \times 10^{-9}$ to $22.4 \times 10^{-9} \mathrm{~mol} \mathrm{~cm} \mathrm{~cm}^{2} \cdot \mathrm{s}^{-1}$ for blue LED and $2.2 \times$ $10^{-9}$ to $14.9 \times 10^{-9} \mathrm{~mol} \cdot \mathrm{cm}^{2} \mathrm{~s}-\mathrm{mol} \cdot \mathrm{cm}^{2} \cdot \mathrm{s}^{-1}$ for red LED respectively. A $25 \mu \mathrm{m}$ diameter PT wire (Good fellow, Cambridge, UK) was sealed into a $5 \mathrm{~cm}$ glass capillary prepared by Vertical pull pin instrument (PC-10, Japan). The ultramicroelectrode (UME) was polished by a grinding instrument (EG-400, Japan) and micro-polishing cloth with 1.0, 0.3 and $0.05 \mu \mathrm{m}$ alumina powder. Then the UME was sharpened conically to an RG of 10 , where RG is the ratio between the diameters of the glass sheath and the PT disk. The approach curves are given as normalized UME current IT vs. normalized distance L. the position Zmax at which mechanical contact of the UME with the sensitized sample and distance does the active electrode area of the sample at $\mathrm{Zmax}$. $\mathrm{L}$ is obtained from the vertical position $\mathrm{z}$ increasing with an approach to $\mathrm{NiO} / \mathrm{P} 1$ sample. There for the possible distance between the sub-straight and tip $200 \mu \mathrm{m} \pm$ do, potentials at the tip ET $=0.7 \mathrm{~V}$. The potential of UME was selected after recording a cyclic voltammogram ET was taken well in the region of the diffusion-controlled $[I]$ oxidation current such that insignificant variations of the reference electrode potential would not change the UME Current [23] [24].

\section{Results and Discussion}

\subsection{SECM Feedback Mode of P1 Sensitized NiO Film}

In feedback mode ultra-micro electrode (UME) immersed in an electrolyte solution and operated as working electrode in the system [25]. We were measured SECM approach curve of $\mathrm{P} 1 / \mathrm{NiO}$ sample at different illumination intensities to explore the influence of light wavelength on dye regeneration. Figure 1(b) shows absorption spectra of P1 the UV-vis absorption spectra, show one minor absorption band looking at $300-420 \mathrm{~nm}$ and one prominent band at $400-700$ $\mathrm{nm}$, respectively, which are ascribed to $\pi-\pi^{*}$ transitions of the conjugated chromophores. Figure 2(a) shows theoretical approach curves of UME over sensitized nickel oxide, it represents the finite kinetic reaction at UME and diffusion-controlled re-action on the surface of sensitized nickel oxide (P1/NiO). Curve\#1 represents the electrochemical conversion of $I 3$ to $I$ at the surface of sensitized nickel oxide $(\mathrm{P} 1 / \mathrm{NiO})$ called positive feedback, curve\#2 represents the 
current response to finite reaction kinetics on illuminated sensitized nickel oxide.

In dark the approach curve\#3 of dye sensitized nickel oxide (P1/NiO) identical to insulating surface, which hinders the diffusion of $I$ towards the UME, named as negative feedback [26] [27] [28].

Figure 2(b) shows approach curves of blue LED $\left(13.9 \times 10^{-9} \mathrm{~mol} \cdot \mathrm{cm}^{-2} \cdot \mathrm{s}^{-1}\right)$ and red LED, $\left(J_{h_{V}}=2.2 \times 10^{-9} \mathrm{~mol} \cdot \mathrm{cm}^{-2} \cdot \mathrm{s}^{-1}\right)$ which represent the depends of UME current on the flux density of illuminated light. There are number of processes that affect charge transfer kinetics in NiO/P1/electrolyte/UME interface such as light absorption and hole injection from excited dye to valence band potential of the nickel oxide, diffusion of the $I$ redox mediator, ET at the illuminated dye-sensitized $\mathrm{NiO} /$ electrolyte interface, hole conduction across the nano porous $\mathrm{NiO}$ film and ET at the $\mathrm{NiO}$ film/FTO interface.

Figure 3 shows that charge transport process in illuminated $\mathrm{NiO} /$ dye/electrolyte interface. When excited dye injected holes into valence band of nickel oxide (NiO) schemes 1 and 2 charge separation and hole injection. The reaction of ground state dye reduced with electrolyte lead electron transport across nickel oxide (NiO) film to back contact and lead to charge regeneration scheme 3 and 4 [29] [30]. The dye regeneration reaction rate constant $k_{\text {eff }}$ at $\mathrm{NiO} / \mathrm{P} 1 / \mathrm{UME}$ interface related to electron transfer kinetics on the basis of SECM feedback mode expressed as function of, $k_{\text {red }}, \Phi_{\text {hv }}, \Gamma_{\mathrm{D}^{o}}, J_{h v}$ and [ $I$ ] given by Equation (1) [31] [32].
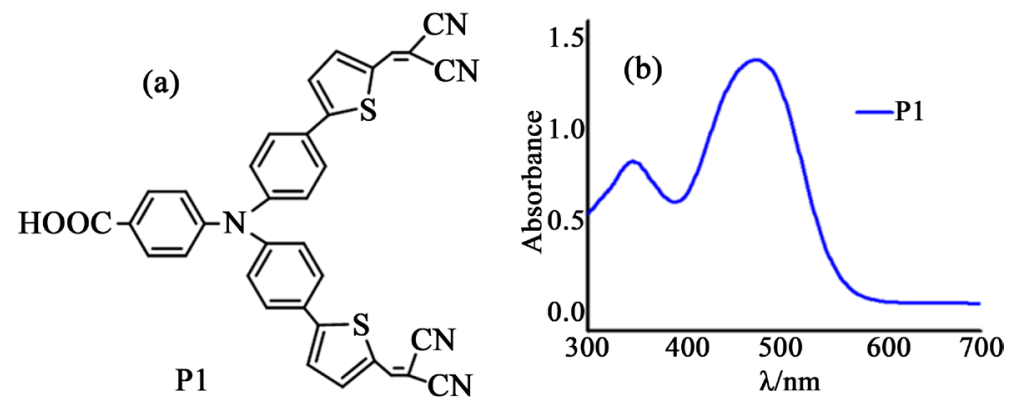

Figure 1. (a) Molecular structure of P1 dye; (b) Absorption spectra of P1.
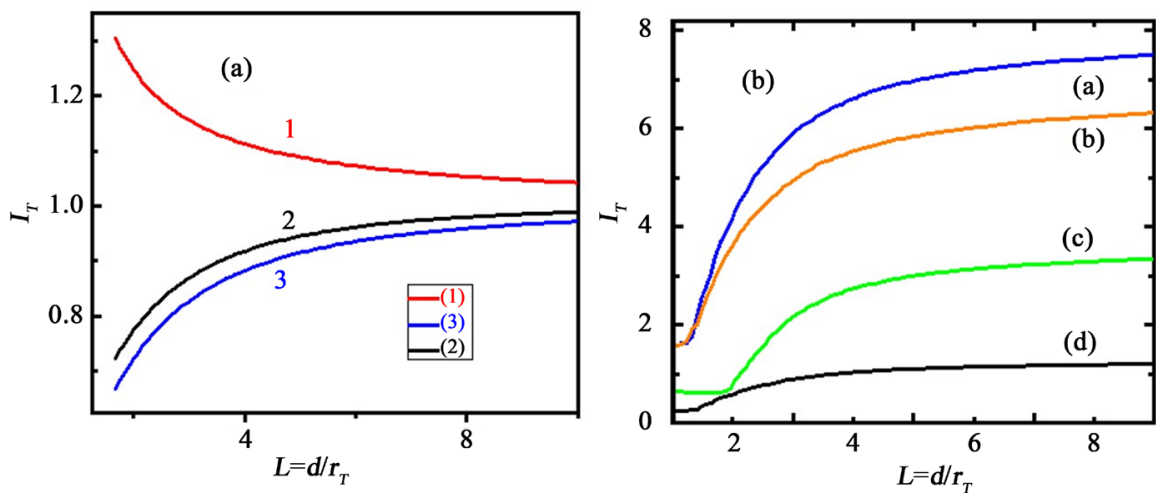

Figure 2. (a) Theoretical approach curves for a tip electrode over a $\mathrm{P} 1 / \mathrm{NiO}$ conductive and UME. Solid lines are computed for RG $=10$ from (1) Equation (1) (green curve) and Equation (2) (blue curve (3) red (b) approach curves with different illumination intensity of blue LED and red LED. 


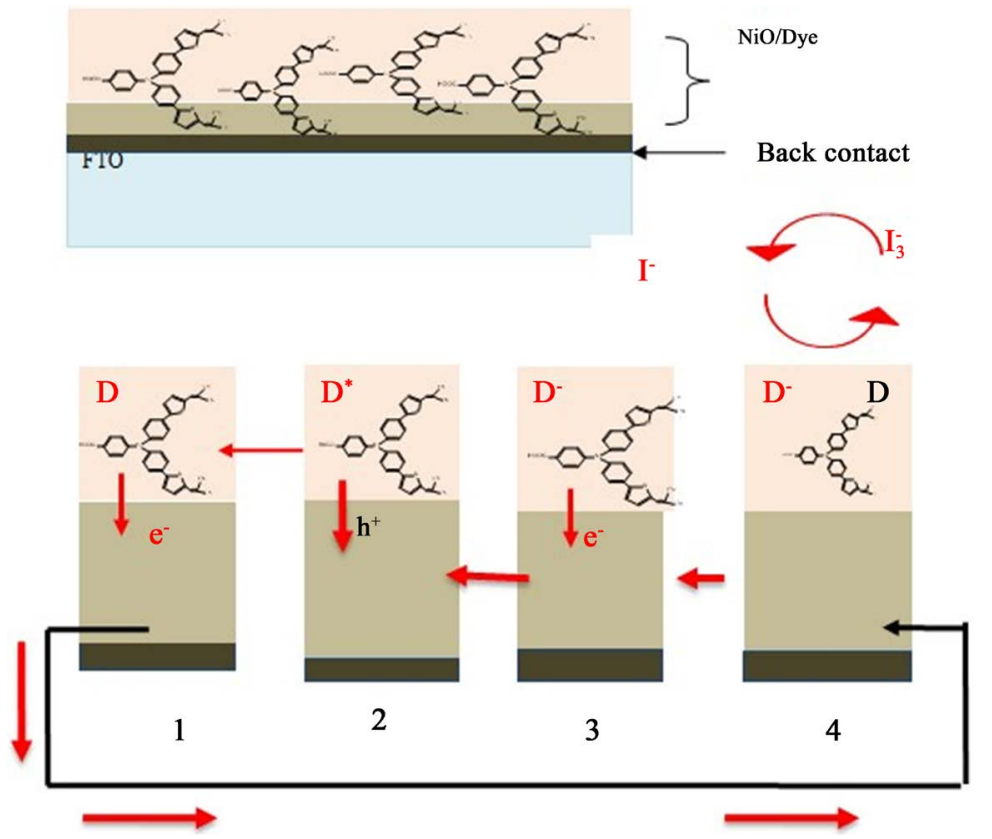

Figure 3. Simplified model of the charge transport between in illuminated NiO/P1 electrode.
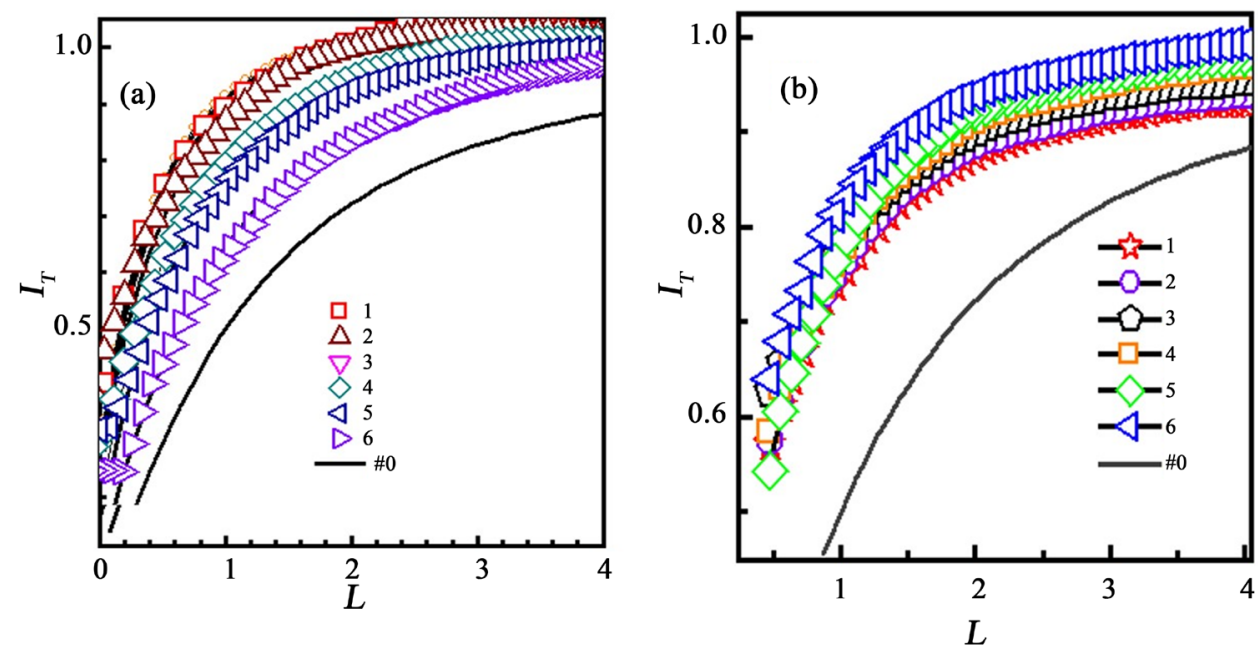

Figure 4. Comparison of normalized SECM approach curves between electrolyte of $1 \mathrm{mM}+0.1 \mathrm{M}$ LiTFS inert supporting electrolyte with Pt UME $(\mathrm{d}=25 \mu \mathrm{m})$ on $\mathrm{P} 1 / \mathrm{NiO}$ under illumination (a) blue LED Photon flux density $\mathrm{J}_{\mathrm{hv}} / 10^{-9} \mathrm{~mol} \cdot \mathrm{cm}^{-2} \cdot \mathrm{s}^{-1}$ (1) 2.2 , (2) 6.1 , (3) 11.8 , (4) 13.9, (5) 19.8, (6) 22.4. (b) red LED Jh $/ 10^{-9} \mathrm{~mol} \cdot \mathrm{cm}^{-2} \cdot \mathrm{s}^{-1}$ (1) 4.19 , (2) 6.81, (3) 9.44, (4) 12.08 , (5) 13.11, (6) 14.68.

$$
k_{\text {eff }}=\frac{3 \Gamma_{\mathrm{D}^{\circ}} \Phi_{\mathrm{hv}} J_{\mathrm{hv}} k_{\mathrm{red}}}{6 k_{\mathrm{red}}\left[\mathrm{I}^{-}\right]-2 \Phi_{\mathrm{hv}} J_{\mathrm{hv}}}
$$

where $\Phi_{\mathrm{hv}}$, absorption cross section, $k_{\mathrm{inj}}$ the rate constant of hole injection, $J_{h v}$ the photon flux, $\Gamma_{\mathrm{D}^{\circ}}$ dye content at ground level and $k_{\text {red }}$ extracted reduction rate constant.

In order to investigate dependence of dye regeneration on light wavelength we have carried approach curve measurement of sensitized nickel oxide film. Figure 
4(a) and Figure 4(b) show normalized approach curve of UME on P1/NiO film in blue and red LED illuminations. As photon density $J_{h v}$ increased from $2.2 \times$ $10^{-9}$ to $22.4 \times 10^{-9} \mathrm{~mol} \cdot \mathrm{cm}^{-2} \cdot \mathrm{s}^{-1} k_{\text {eff }}$ increased from $6.02 \times 10^{-3} \mathrm{~cm} \cdot \mathrm{s}^{-1}$ to $20.22 \times$ $10^{-3} \mathrm{~cm} \cdot \mathrm{s}^{-1}$ in blue illumination. Similarly, as red LED $J_{h v}$ increased from $2.2 \times$ $10^{-9}$ to $14.68 \times 10^{-9} \mathrm{~mol} \cdot \mathrm{cm}^{-2} \cdot \mathrm{s}^{-1}$ red illumination $k_{\text {eff }}$ increased from $3.54 \times 10^{-3}$ to $10.01 \times 10^{-3} \mathrm{~cm} \cdot \mathrm{s}^{-1}$. For example, at $J_{h V}=2.2 \times 10^{-9} \mathrm{~mol} \cdot \mathrm{cm}^{-2} \cdot \mathrm{s}^{-1}$ its $k_{\text {eff }}=6.02$ $\times 10^{-3} \mathrm{~cm} \cdot \mathrm{s}^{-1}$ and at $J_{h V}=22.4 \times 10^{-9} \mathrm{~mol} \cdot \mathrm{cm}^{-2} \cdot \mathrm{s}^{-1}$ its $k_{\text {eff }}=20.22 \times 10^{-3} \mathrm{~cm} \cdot \mathrm{s}^{-1}$ in blue LED illumination. This means when $J_{h v}$ increased ten times keff increased more than three times in blue illumination.

In the same way for $J_{h V}=2.2 \times 10^{-9} \mathrm{~mol} \cdot \mathrm{cm}^{-2} \cdot \mathrm{s}^{-1}$ its, $k_{\text {eff }}=3.54 \times 10^{-3} \mathrm{~cm} \cdot \mathrm{s}^{-1}$, at $J_{h V}=14.68 \times 10^{-9} \mathrm{~mol} \cdot \mathrm{cm}^{-2} \cdot \mathrm{s}^{-1}$, its $k_{e f f}=3.54 \times 10^{-3} \mathrm{~cm} \cdot \mathrm{s}^{-1}$ in red illumination as shown (Table 1). This variation of rate constant $k_{\text {eff }}$ with the variation of $J_{h v}$ clearly shows that remarkable influence of the wavelength and light intensity on dye regeneration kinetics. Another finding elucidates that $k_{\text {eff }}$ with blue LED more than two times higher than $k_{\text {eff }}$ of red LED. The higher value of $k_{\text {eff }}$ for blue LED lead to the maximum absorption of P1 dye around $490 \mathrm{~nm}$ as shown Figure 1(b).

\subsection{SECM Approach Curves on P1/NiO Electrodes: Effect of Solvent}

The overall performance dye sensitized solar cell strongly affected by the numbers of parameters such as nature of solvent, solvent permittivity and dye extinction coefficient [33]. Figure 5 shows normalized approach curves at different photon flux density $J_{h V}$ in (a) methanol (b) propylene carbonate for electrolyte

Table 1. Normalized apparent rate constants $\mathrm{k}$ and apparent rate constants $k_{\text {eff }}=k \mathrm{D} / \mathrm{r}_{\mathrm{T}}$ obtained for the reduction of photo excited $\mathrm{D}^{-}$by $I, \mathrm{D}=8.61 \times 10^{-5} \mathrm{~cm} \cdot \mathrm{s}^{-1}$.

\begin{tabular}{cccc}
\hline$J_{h v} / 10^{-9} \mathrm{~mol} \cdot \mathrm{cm}^{-2} \cdot \mathbf{s}^{-1}$ & Curve\# & $\boldsymbol{\kappa}$ & $\boldsymbol{k}_{\text {eff }} / 10^{-3} \mathrm{~cm} \cdot \mathrm{s}^{-1}$ \\
\hline (a) Blue & 6 & 0.087 & 6.02 \\
2.2 & 5 & 0.178 & 12.31 \\
6.1 & 4 & 0.242 & 16.71 \\
11.8 & 3 & 0.255 & 17.62 \\
13.9 & 2 & 0.283 & 19.51 \\
19.8 & 1 & 0.294 & 20.22 \\
22.4 & & & \\
(b) Red & 6 & 0.053 & 3.54 \\
2.2 & 5 & 0.081 & 5.55 \\
4.19 & 4 & 0.106 & 7.32 \\
6.81 & 3 & 0.123 & 8.52 \\
9.44 & 2 & 0.137 & 9.41 \\
12.06 & 1 & 0.241 & 10.01 \\
14.68 & & &
\end{tabular}



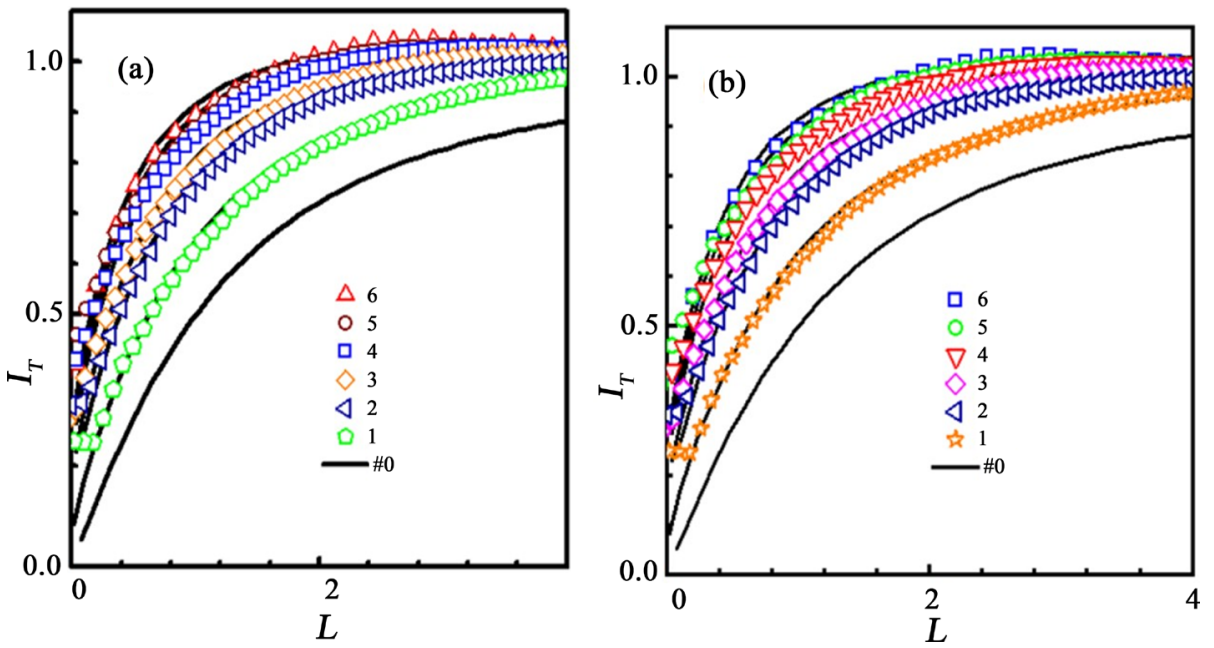

Figure 5. Normalized approach curves at of blue illumination with electrolyte of [1mM] (a) In methanol solvent rate constant $\kappa$ (1) 0.087 (2) 0.178 (3) 0.242 (4) 0.255 (5) 0.283 (6) 0.294 (b) In propylene carbonate solvent rate constant $\kappa$ (1) (1) 0.0062 (2) 0.0122 (3) 0.0165 (4) 0.0175 (5) 0.0194 (6) 0.0213.

$[I]$ of $1 \mathrm{mM}$. When sensitized nickel oxide illuminated in back side the current was significantly higher than dark (curves \#1-6) as shown in Table 2. For blue illumination as $J_{h v}$ increased from $2.2 \times 10^{-9}$ to $22.4 \times 10^{-9} \mathrm{~mol} \cdot \mathrm{cm}^{-2} \cdot \mathrm{s}^{-1}$ as $k_{\text {eff }}$ increased from $6.02 \times 10^{-3}$ to $22 \times 10^{-3} \mathrm{~cm} \cdot \mathrm{s}^{-1}$ in acetonitrile, $k_{\text {eff }}$ increased from $0.97 \times 10^{-3}$ to $3.13 \times 10^{-3} \mathrm{~cm} \cdot \mathrm{s}^{-1}$ in ethanol, $k_{\text {eff }}$ increased from $1.73 \times 10^{-3}$ to 5.54 $\times 10^{-3} \mathrm{~cm} \cdot \mathrm{s}^{-1}$ in methanol and $k_{\text {eff }}$ increased from $0.838 \times 10^{-3}$ to $2.69 \times 10^{-3}$ $\mathrm{cm} \cdot \mathrm{s}^{-1}$ in propylene carbonate s respectively as shown in Figure 2(a) and Figure 2(b). Approach curves in acetonitrile and ethanol solvents documented in supporting information SI Figure 3(a) and Figure 3(b). In this experiment regeneration parameters reduction rate constant and absorption cross-section $\left(k_{\text {red }}\right.$, $\left.\Phi_{\mathrm{hv}}\right)$ of $\left(7.96 \times 10^{5} \mathrm{~mol}^{-1} \cdot \mathrm{cm}^{3} \cdot \mathrm{s}^{-1}, 7.98 \times 10^{6} \mathrm{~cm}^{2} \cdot \mathrm{mol}^{-1}\right)$ in acetonitrile $\left(1.24 \times 10^{5}\right.$ $\left.\mathrm{cm}^{3} \cdot \mathrm{s}^{-1}, 3.57 \times 10^{5} \mathrm{~cm}^{2} \cdot \mathrm{mol}^{-1}\right)$ in ethanol $\left(2.18 \times 10^{5} \mathrm{~mol}^{-1} \cdot \mathrm{cm}^{3} \cdot \mathrm{s}^{-1}, 4.19 \times 10^{6}\right.$ $\left.\mathrm{cm}^{2} \cdot \mathrm{mol}^{-1}\right)$ in methanol and $\left(1.02 \times 10^{5} \mathrm{~mol}^{-1} \cdot \mathrm{cm}^{3}, 1.53 \times 10^{5} \mathrm{~cm}^{2} \cdot \mathrm{mol}^{-1}\right)$ in propylene carbonate respectively (Table 3 ). These considerable variations of reduction rate constant $k_{\text {red }}$ and absorption cross-section $\Phi_{\mathrm{hv}}$ shows clear evidence of effect of solvent on dye regeneration process.

Figure 6(a) shows Plot of $k_{e f f}$ vs $J_{h V}$ of four different solvents in blue illumination. As our experiment shown the steady-state currents and diffusion coefficient in acetonitrile solvent was significantly higher than, methanol, ethanol and propylene carbonate. The diffusion coefficient $\mathrm{D}$ and tip current $\left[\mathrm{I}_{\mathrm{T}}\right]$ of five times higher than tip current of propylene carbonate, four times of ethanol and two times of methanol. Figure 6(b) shows plot of $k_{\text {eff }}$ vs $\eta$ shows the effect of solvent on dye regeneration. The experimental observations clearly show significant impact of solvent viscosity on regeneration parameters such as $k_{\text {red }}, \mathrm{D}, I_{\mathrm{T}}$ and $\phi_{\mathrm{hv}}$ [34] [35] [36].

This implies that regeneration parameters in acetonitrile are greater than methanol, ethanol and propylene carbonate. As shown in experimental reduction 
rate constant $k_{\text {red }}$ in acetonitrile seven times higher than $k_{\text {red }}$ of propylene carbonate, six times higher than $k_{\text {red }}$ of ethanol and $k_{\text {red }}$ of two times higher than of methanol. This realizes that acetonitrile is preferable solvent for dye regeneration and significant impact of solvent nature on regeneration kinetics (Table 3).

Figure 6(b) shows that when viscosity of solvent increases, dye regeneration parameters such as $k_{e f f} k_{\text {red }}, D$ and $\phi_{\text {hv }}$ decrease inversely. This finding explored

Table 2. Normalized rate constants $k$ and apparent rate constants $k_{\text {eff }}=k D / r_{T}$ obtained for the reduction of photo excited $D^{-}$by $I, D=8.61 \times 10^{-5} \mathrm{~cm}^{2} \cdot \mathrm{s}^{-1}$ in acetonitrile, $D=$ $3.19 \times 10^{-5} \mathrm{~cm}^{2} \cdot \mathrm{s}^{-1}$ methanol, $D=1.85 \times 10^{-5} \mathrm{~cm}^{2} \cdot \mathrm{s}^{-1}$ Ethanol, $D=1.67 \times 10^{-5} \mathrm{~cm}^{2} \cdot \mathrm{s}^{-1}$ in different solvent.

\begin{tabular}{|c|c|c|c|}
\hline$J_{h v} / 10^{-9} \mathrm{~mol} \cdot \mathrm{cm}^{-2} \cdot \mathrm{s}^{-1}$ & Curve\# & $\kappa$ & $k_{\text {eff }} / 10^{-3} \mathrm{~cm} \cdot \mathrm{s}^{-1}$ \\
\hline \multicolumn{4}{|l|}{ (a) acetonitrile } \\
\hline 2.2 & 1 & 0.087 & 6.02 \\
\hline 6.1 & 2 & 0.178 & 12.31 \\
\hline 11.8 & 3 & 0.242 & 16.71 \\
\hline 13.9 & 4 & 0.255 & 17.62 \\
\hline 19.8 & 5 & 0.283 & 19.51 \\
\hline 22.4 & 6 & 0.294 & 20.22 \\
\hline \multicolumn{4}{|l|}{ (b) Methanol } \\
\hline 2.2 & 1 & 0.0067 & 1.73 \\
\hline 6.1 & 2 & 0.0132 & 3.38 \\
\hline 11.8 & 3 & 0.0178 & 4.56 \\
\hline 13.9 & 4 & 0.0189 & 4.83 \\
\hline 19.8 & 5 & 0.0214 & 5.37 \\
\hline 22.4 & 6 & 0.0219 & 5.54 \\
\hline \multicolumn{4}{|l|}{ (c) Ethanol } \\
\hline 2.2 & 1 & 0.0655 & 0.97 \\
\hline 6.1 & 2 & 0.129 & 1.91 \\
\hline 11.8 & 3 & 0.174 & 2.58 \\
\hline 13.9 & 4 & 0.185 & 2.73 \\
\hline 19.8 & 5 & 0.205 & 3.04 \\
\hline 22.4 & 6 & 0.213 & 3.13 \\
\hline \multicolumn{4}{|l|}{ (d) poly carbonate } \\
\hline 2.2 & 1 & 0.0062 & 0.838 \\
\hline 6.1 & 2 & 0.0122 & 1.64 \\
\hline 11.8 & 3 & 0.0165 & 2.21 \\
\hline 13.9 & 4 & 0.0175 & 2.34 \\
\hline 19.8 & 5 & 0.0194 & 2.61 \\
\hline 22.4 & 6 & 0.0213 & 2.69 \\
\hline
\end{tabular}



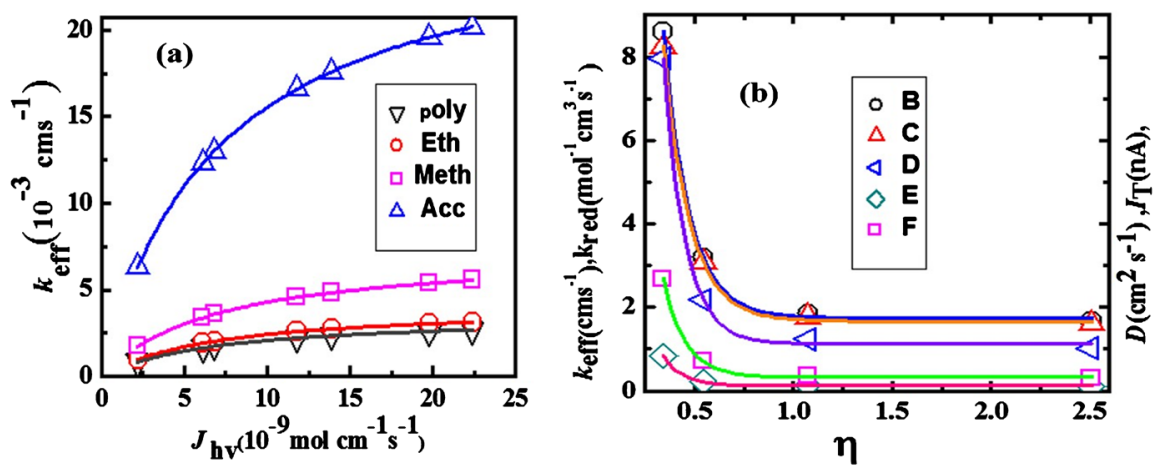

Figure 6. Plot of $k_{\text {eff }}$ vs $J_{h V}$ of (a) acetonitrile ( $\square$ ), methanol $(\Delta)$, ethanol (O) propylene carbonate $(\nabla)$ in blue illumination (b) graph of viscosity $\eta$ vs, [B] $D,[\mathrm{c}] I_{T}$, [D] $k_{\text {red }}$ [E] $\phi_{\mathrm{hv}}$ in blue and $[\mathrm{F}] \phi_{\mathrm{hv}}$ red illumination

with the diffusion coefficient of the reactants, $D, k_{e f \beta} \kappa$ normalized rate constant varied with solvent viscosity, $\eta$ as expressed by stokes-Einstein equation.

$$
k_{\mathrm{eff}}=\frac{K}{r_{T}}\left(\frac{\kappa T}{6 \pi r \eta}\right)
$$

where $K$ is Boltizmann's constant, $r_{T}$ radius of UME and $r$ the hydrodynamics radius of the diffusing species, $T$ temperature [37] [38].

According to photo modulated voltammeter the viscosity of the solvent clearly affects diffusion coefficient and diffusion length of redox intermediates. When dye illuminated, it led charge separation, hole injection into $\mathrm{NiO}$ valence band, regenerate to ground state as Equation 3(a), and iodine-based intermediates which accountable for dye regeneration processes Equation 3(b) [39].

$$
\begin{gathered}
\mathrm{I}_{3}^{-}+\mathrm{e}^{-} \rightarrow \mathrm{I}_{2}^{--}+\mathrm{I}^{\cdot} \\
\mathrm{I}_{2}^{--}+\left(\mathrm{e}^{-}\right) \mathrm{NiO} \rightarrow 2 \mathrm{I}^{-}+\mathrm{NiO}(+) \\
\Delta G_{\text {reg }}^{0}=e\left(E^{\mathrm{o}}\left(\mathrm{D} / \mathrm{D}^{-}\right)\right)-E^{\mathrm{o}}\left(\mathrm{I}_{3}^{-} / \mathrm{I}_{2}^{--}\right)
\end{gathered}
$$

This implies that regeneration parameters in acetonitrile greater than methanol, ethanol and propylene carbonate. As shown in experimental reduction rate constant $k_{\text {red }}$ in acetonitrile seven times higher than $k_{\text {red }}$ of propylene carbonate, six times higher than $k_{\text {red }}$ of ethanol and $k_{\text {red }}$ of two times higher than of methanol. This realizes that acetonitrile is preferable solvent for dye regeneration and significant impact of solvent nature on regeneration kinetics (Table 3).

The driving force is difference of the reduction potential of dye and electron reduction potential of $\mathrm{I}_{3}^{-}$in solvents has significant impact on regeneration kinetics. The standard potentials of $E^{\circ}\left(\mathrm{I}_{3}^{-} / \mathrm{I}_{2}^{--}\right)$redox couple in different solvents have been investigated in literature; for acetonitrile $E^{\circ}\left(\mathrm{I}_{3}^{-} / \mathrm{I}_{2}^{-}\right)$of $(-0.58 \mathrm{eV})$ and propylene carbonate $E^{\circ}\left(\mathrm{I}_{3}^{-} / \mathrm{I}_{2}^{-}\right)$of $(-0.64 \mathrm{eV})$. From previous report estimated value of $E^{\circ}\left(\mathrm{P} 1 / \mathrm{P}^{-}\right)$of $(-3.13 \mathrm{eV})$ for P1 dye. The driving force according to (Equation $3(\mathrm{c}))$, in acetonitrile $\Delta G_{\text {reg }}^{\mathrm{o}}$ of $(-2.55 \mathrm{eV})$ higher than propylene carbonate $\Delta G_{\text {reg }}^{\mathrm{o}}$ of $(-2.49 \mathrm{eV})$. Therefore, driving force in different solvents show that dye-electrolyte interaction plays significant role on dye regeneration kinetics. 
Table 3. Feedback model reduction rate $k_{\text {red }}$, the regeneration rate, $k_{\text {eff }}$ normalized rate constant $k$, and absorption cross-section $\phi_{\text {hv }}$ of $\mathrm{P} 1$-sensitized $\mathrm{NiO}$ photo electrochemical electrodes in different electrolyte solvent] $k_{\text {red }}$ reduction rate constant and $\Phi_{\text {hv. }}$

\begin{tabular}{ccccc}
\hline Solvent $(\boldsymbol{\eta})$ & $\mathrm{D} / 10^{-5} \mathrm{~cm}^{-2} \cdot \mathbf{s}$ & $\mathrm{I}_{\mathrm{T} /} \mathbf{1 0 ^ { - 8 }} \mathrm{A}$ & $\mathrm{k}_{\mathrm{red}} / 10^{5} \mathrm{~mol}^{-1} \cdot \mathrm{cm}^{3} \cdot \mathrm{s}^{-1}$ & $\Phi_{\mathrm{hv}} \mathrm{cm}^{2} \cdot \mathrm{mol}^{-1}$ \\
\hline Acetonitrile (0.34) & 8.61 & 8.235 & 7.96 & $7.98 \times 10^{6}$ \\
Methanol (1.074) & 3.19 & 3.078 & 2.18 & $4.19 \times 10^{6}$ \\
Ethanol (0.544) & 1.85 & 1.771 & 1.24 & $3.57 \times 10^{5}$ \\
P/carbonate (2.51) & 1.67 & 1.596 & 1.02 & $1.53 \times 10^{5}$ \\
\hline
\end{tabular}

\section{Conclusion}

Scanning electrochemical microscopy has been powerful technique for electron transfer reactions in sensitized electrode/electrolyte interface. The SECM study shows that the significant difference in the regeneration parameters of illuminated dye sensitized $\mathrm{NiO}$ samples with different illumination intensity and wavelength of blue and red LEDs, with different solvent. We found significant variation of regeneration kinetic parameters such as regeneration rate constant $\left(k_{\text {eff }}\right)$, reduction rate constant $\left(k_{\text {red }}\right)$ and absorption cross section $\left(\Phi_{\text {hv }}\right)$ in different illumination intensity and different solvent. We found, $k_{\mathrm{red}} 7.96 \times 10^{5} \mathrm{~mol}^{-1} \cdot \mathrm{cm}^{3} \cdot \mathrm{s}^{-1}$ for acetonitrile, $2.18 \times 10^{5} \mathrm{~mol}^{-1} \cdot \mathrm{cm}^{3} \cdot \mathrm{s}^{-1}$ for methanol, $1.24 \times 10^{5} \mathrm{~mol}^{-1} \cdot \mathrm{cm}^{3} \cdot \mathrm{s}^{-1}$ for ethanol and $1.24 \times 10^{5} \mathrm{~mol}^{-1} \cdot \mathrm{cm}^{3} \cdot \mathrm{s}^{-1}$ for P/carbonate. Therefore, SECM method is new dimension to study dye regeneration factor to improve energy conversion efficiencies for the P-type DSSC.

\section{Acknowledgements}

A.G.A. gratefully acknowledges the Chinese Scholarship Counsel (CSC) for the Ph.D. fellowship.

\section{Conflicts of Interest}

The authors declare no conflicts of interest regarding the publication of this paper.

\section{References}

[1] O’Regan, B. and Grätzel, M. (1999) A Low-Cost, High-Efficiency Solar Cell Based on Dye-Sensitized Colloidal $\mathrm{TiO}_{2}$ Films. Nature, 353, 737-740. https://doi.org/10.1038/353737a0

[2] Hagfeldt, A. and Graetzel, M. (1995) Light-Induced Redox Reactions in Nanocrystalline Systems. Chemical Reviews, 95, 49-68.

https://doi.org/10.1021/cr00033a003

[3] Grätzel, M. (2003) Review Dye-Sensitized Solar Cells. Journal of Photochemistry and Photobiology C: Photochemistry Reviews, 4, 145-153. https://doi.org/10.1016/S1389-5567(03)00026-1

[4] Haque, S.A., Palomares, E., Cho, B.M., Green, A.N.M., Hirata, N., Klug, D.R., Durrant, J.R. and Durrant, J. (2005) Charge Separation versus Recombination in 
Dye-Sensitized Nanocrystalline Solar Cells: The Minimization of Kinetic Redundancy. Journal of the American Chemical Society, 127, 3456-3462. https://doi.org/10.1021/ja0460357

[5] Chiba, Y., Islam, A., Watanabe, Y., Komiya, R., Koide, N. and Han, L. (2006) Dye-Sensitized Solar Cells with Conversion Efficiency of 11.1\%. Japanese Journal of Applied Physics, 45, L638-L640. https://doi.org/10.1143/JJAP.45.L638

[6] Rajab, F.M. (2016) Effect of Solvent, Dye-Loading Time, and Dye Choice on the Performance of Dye-Sensitized Solar Cells. Journal of Nanomaterials, 2016, Article ID: 3703167. https://doi.org/10.1155/2016/3703167

[7] Hagfeldt, A., Boschloo, G., Sun, L.C., Kloo, L. and Pettersson, H. (2010) Dye-Sensitized Solar Cells. Chemical Reviews, 110, 6595-6663. https://doi.org/10.1021/cr900356p

[8] Rensmo, H., Keis, K., Lindström, H., Södergren, S., Solbrand, A., Hagfeldt, A., Lindquist, S.E., Wang, L.N. and Muhammed, M. (1999) High Light-to-Energy Conversion Efficiencies for Solar Cells Based on Nanostructured ZnO Electrodes. The Journal of Physical Chemistry B, 103, 8940-8943.

[9] Odobel, F., Pleux, L.L., Pellegrin, Y. and Blart, E. (2010) New Photovoltaic Devices Based on the Sensitization of p-Type Semiconductors: Challenges and Opportunities. Accounts of Chemical Research, 43, 1063-1071. https://doi.org/10.1021/ar900275b

[10] He, J., et al. (2000) Dye-Sensitized Nanostructured Tandem Cell-First Demonstrated Cell with a Dye-Sensitized Photocathode. Solar Energy Materials \& Solar Cells, 62, 265-273. https://doi.org/10.1016/S0927-0248(99)00168-3

[11] Nazeeruddin, M.K., De Angelis, F., Fantacci, S., Selloni, A., Viscardi, G., Liska, P., Ito, S., Takeru, B. and Grätzel, M. (2005) Combined Experimental and DFT-TDDFT Computational Study of Photoelectrochemical Cell Ruthenium Sensitizers. Journal of the American Chemical Society, 127, 16835-16847. https://doi.org/10.1021/ja0524671

[12] Lee, Y.H., Park, J.Y., Thogiti, S., Cheruku, R. and Kim, J.H. (2016) Application of CBZ Dimer, C343 and SQ Dye as Photosensitizers for pn-Tandem DSCs. Electronic Materials Letters, 12, 524-529. https://doi.org/10.1007/s13391-016-4017-9

[13] Gibson, E.A., Le Pleux, L., Fortage, J., Pellegrin, Y., Blart, E., Odobel, F., Hagfeldt, A. and Boschloo, G. (2012) Role of the Triiodide/Iodide Redox Couple in Dye Regeneration in p-Type Dye-Sensitized Solar Cells. Langmuir, 28, 6485-649. https://doi.org/10.1021/la300215q

[14] Qin, P., et al. (2008) Design of an Organic Chromophore for P-Type Dye-Sensitized Solar Cells. Journal of the American Chemical Society, 130, 8570-8571. https://doi.org/10.1021/ja8001474

[15] Qin, P., Wiberg, J., Gibson, E.A., Linder, M., Li, L., Brinck, T., Hagfeldt, A., Albinsson, B. and Sun, L.C. (2010) Synthesis and Mechanistic Studies of Organic Chromophores with Different Energy Levels for p-Type Dye-Sensitized Solar Cells. The Journal of Physical Chemistry C, 114, 4738-4748. https://doi.org/10.1021/jp911091n

[16] Daeneke, T., Mozer, A.J., Kwon, T.-H., Duffy, N.W., Holmes, A.B., Bach, U. and Spiccia, L. (2012) Dye Regeneration and Charge Recombination in Dye-Sensitized Solar Cells with Ferrocene Derivatives as Redox Mediators. Energy \& Environmental Science, 5, 7090-7099. https://doi.org/10.1039/c2ee21257a

[17] Daeneke, T., Mozer, A.J., Uemura, Y., Makuta, S., Fekete, M., Tachibana, Y., Koumura, N., Bach, U. and Spiccia, L. (2012) Dye Regeneration Kinetics in Dye-Sensitized Solar Cells. Journal of the American Chemical Society, 134, 16925-16928. https://doi.org/10.1021/ja3054578 
[18] Feldt, S.M., Lohse, P.W., Kessler, F., Nazeeruddin, M.K., Grätzel, M., Boschloo, G. and Hagfeldt, A. (2013) Regeneration and Recombination Kinetics in Cobalt Polypyridine Based Dye-Sensitized Solar Cells, Explained Using Marcus Theory. Physical Chemistry Chemical Physics, 15, 7087-7097. https://doi.org/10.1039/c3cp50997d

[19] Zhang, Z.P., Ito, S., Moser, J.-E., Zakeeruddin, S.M. and Grätzel, M. (2009) Influence of Iodide Concentration on the Efficiency and Stability of Dye-Sensitized Solar Cell Containing Non-Volatile Electrolyte. ChemPhysChem, 10, 1834-1838. https://doi.org/10.1002/cphc.200900199

[20] Griffith, M.J., Sunahara, K., Furube, A., Mozer, A.J., Officer, D.L., Wagner, P., Wallace, G.G. and Mori, S. (2013) Cation Exchange at Semiconducting Oxide Surfaces: Origin of Light-Induced Performance Increases in Porphyrin Dye-Sensitized Solar Cells. The Journal of Physical Chemistry C, 117, 11885-11898.

https://doi.org/10.1021/jp3067712

[21] Alemu, G., Cui, J., Cao, K., Li, J.P., Shen, Y. and Wang, M.K. (2014) Investigation of the Regeneration Kinetics of Organic Dyes with Pyridine Ring Anchoring Groups by Scanning Electrochemical Microscopy. RSC Advances, 4, 51374-51380. https://doi.org/10.1039/C4RA07908F

[22] Alemu, G., Li, J.P., Cui, J., Xu, X.B., Zhang, B.Y., Cao, K., Shen, Y., Cheng, Y.B. and Wang, M.K. (2015) Investigation on Regeneration Kinetics at Perovskite/Oxide Interface with Scanning Electrochemical Microscopy. Journal of Materials Chemistry A, 20, 1-7.

[23] Zhang, B., Xu, X., Zhang, D., Huang, D., Li, S., Zhang, Y., Zhan, F., Deng, M., He, Y., Chen, W., Shin, Y. and Wang, M. (2014) Investigation of Dye Regeneration Kinetics in Sensitized Solar Cells by Scanning Electrochemical Microscopy. ChemPhysChem, 15, 1182-1189. https://doi.org/10.1002/cphc.201301076

[24] Alemu, G., Zhang, B.Y., Li, J.P., Xu, X.B., Cui, J., Shen, Y. and Wang, M.K. (2014) Investigation of Dye-Regeneration Kinetics at Dye-Sensitized $p$-Type $\mathrm{CuCrO}_{2}$ FILM/Electrolytes Interface with Scanning Electrochemical Microscopy. Nano, 9, Article ID: 1440008. https://doi.org/10.1142/S1793292014400086

[25] Shen, Y., Nonomura, K., Schlettwein, D., Zhao, C. and Wittstock, G. (2006) Photoelectrochemical Kinetics of Eosin Y-Sensitized Zinc Oxide Films Investigated by Scanning Electrochemical Microscopy. Chemistry - A European Journal, 12, 5832-5839. https://doi.org/10.1002/chem.200501241

[26] Wittstock, G., Burchardt, M., Pust, S.E., Shen, Y. and Zhao, C. (2007) Scanning Electrochemical Microscopy for Direct Imaging of Reaction Rates. Angewandte Chemie International Edition, 46, 1584-1617. https://doi.org/10.1002/anie.200602750

[27] Sun, P., Laforge, F.O. and Mirkin, M.V. (2007) Scanning Electrochemical Microscopy in the 21st Century. Physical Chemistry Chemical Physics, 9, 802-823. https://doi.org/10.1039/B612259K

[28] Morandeira, A., Fortage, J., Edvinsson, T., Pleux, L.L., Blart, E., Boschloo, G., Hagfeldt, A., Hammarstro, L. and Odobel, F. (2008) Improved Photon-to-Current Conversion Efficiency with a Nanoporous p-Type NiO Electrode by the Use of a Sensitizer-Acceptor Dyad. The Journal of Physical Chemistry C, 112, 1721-1728. https://doi.org/10.1021/jp077446n

[29] Shen, Y., Nonomura, K., Schlettwein, D., Zhao, C. and Wittstock, G. (2009) Photoelectrochemical Kinetics of Eosin Y-Sensitized Zinc Oxide Films Investigated by Scanning Electrochemical Microscopy under Illumination with Different LED. Electrochimica Acta, 55, 458-464. https://doi.org/10.1016/j.electacta.2009.08.062 
[30] Zhang, X.L., Huang, F.Z., Nattestad, A., Wang, K., Fu, D.C., Mishra, A., Bäuerle, P., Bach, U. and Cheng, Y.-B. (2011) Enhanced Open-Circuit Voltage of p-Type DSC with Highly Crystalline NiO Nanoparticles. Chemical Communications, 47, 4808-4810. https://doi.org/10.1039/c0cc05445c

[31] Lu, H.-P., Mai, C.-L., Tsia, C.-Y., Hsu, S.-J., Hsieh, C.-P., Chiu, C.-L., Yeh, C.-Y. and Diau, E.W.-G. (2009) Design and Characterization of Highly Efficient Porphyrin Sensitizers for Green See-Through Dye-Sensitized Solar Cells. Physical Chemistry Chemical Physics, 11, 10270-10274. https://doi.org/10.1039/b917271h

[32] Griffith, M.J., Sunahara, K., Furube, A., Mozer, A.J., Officer, D.L., Wagner, P., Wallace, G.G. and Mori, S. (2013) Cation Exchange at Semiconducting Oxide Surfaces: Origin of Light-Induced Performance Increases in Porphyrin Dye-Sensitized Solar Cells. The Journal of Physical Chemistry C, 117, 11885-11898.

https://doi.org/10.1021/jp3067712

[33] Feldt, S.M., Lohse, P.W., Kessler, F., Nazeeruddin, M.K., Grätzel, M.G. and Hagfeldt, A. (2013) Regeneration and Recombination Kinetics in Cobalt Polypyridine Based Dye-Sensitized Solar Cells, Explained Using Marcus Theory. Physical Chemistry Chemical Physics, 15, 7087-7097. https://doi.org/10.1039/c3cp50997d

[34] Tefashe, U.M., Nonomura, K., Vlachopoulos, N., Hagfeldt, A. and Wittstock, G. (2012) Effect of Cation on Dye Regeneration Kinetics of N719-Sensitized $\mathrm{TiO}_{2}$ Films in Acetonitrile-Based and Ionic-Liquid-Based Electrolytes Investigated by Scanning Electrochemical Microscopy. The Journal of Physical Chemistry C, 116, 4316-4323. https://doi.org/10.1021/jp207671w

[35] Zhan, W. and Bard, A. (2006) Scanning Electrochemical Microscopy. 56. Probing outside and inside Single Giant Liposomes Containing $\mathrm{Ru}(\mathrm{bpy}){ }_{3}{ }^{2+}$. Analytical Chemistry, 78, 726-733. https://doi.org/10.1021/ac051290a

[36] Shen, Y., et al. (2009) Photoelectrochemical Kinetics of Eosin Y-Sensitized Zinc Oxide Films Investigated by Scanning Electrochemical Microscopy under Illumination with Different LED. Electrochimica Acta, 55, 458-464. https://doi.org/10.1016/j.electacta.2009.08.062

[37] Zhang, X, Leddy, J. and Bard, A.J. (1985) Dependence of Rate Constants of Heterogeneous Electron Transfer Reactions on Viscosity. Journal of the American Chemical Society, 107, 3719-3721. https://doi.org/10.1021/ja00298a054

[38] Jono, R., Sumita, M., Tateyama, Y. and Yamashita, K. (2012) Redox Reaction Mechanisms with Non-Triiodide Mediators in Dye-Sensitized Solar Cells by Redox Potential Calculations. The Journal of Physical Chemistry Letters, 3, 3581-3584. https://doi.org/10.1021/jz301589a

[39] Kebede, Z. and Lindquist, S.E. (1999) Donor-Acceptor Interaction between Non-Aqueous Solvents and I2 to Generate I-3, and Its Implication in Dye Sensitized Solar Cells. Solar Energy Materials \& Solar Cells, 57, 259-275.

https://doi.org/10.1016/S0927-0248(98)00178-0 


\section{Supporting Information}

\section{S $I 1$ SECM Measurement}

Normalized heterogeneous rate constants $\kappa$ have been extracted from experimental approach curves by fitting them to an analytical approximation of simulated data evaluated by Amphlett and Denuault.

The formula of Amphlett and Denuault given for RG = 10.2/10. Constants for other selected RG are also available. Normalized approach curves $I_{T}$ vs. $L$ have been calculated from each experiment approach curves $i_{T}(z)$ using $I_{T}=i_{T} / i_{T, \infty}$ and $L=d / r_{T}$. The analytical approximation of Amphlett and Denuault was used for calculating a theoretical current IT for each experimental, normalized distance L [1] [2] [3] [4]

$$
\begin{gathered}
I_{T}(L)=I_{T, \text { ins }}(L)+\left(1-\frac{I_{T, \text { ins }}(L)}{I_{T, \text { cond }}(L)}\right) I_{S}(L) \\
I_{T, \text { con }}(L)=\frac{0.78337}{L}+0.331 \exp ^{\left(-\frac{1.0672}{L}\right)}+0.68 \\
I_{T}^{\text {ins }}=\frac{1}{0.40472+\frac{1.60185}{L}+0.58819 \exp ^{\left(\frac{-2.372294}{L}\right)}} \\
I_{S}(L)=\frac{0.78377}{1+\frac{1}{k L}}+\frac{0.68+0.3315 \exp \left(\frac{-1.0672}{L}\right)}{1+\frac{11 / k L+7.3}{110-40 L}}
\end{gathered}
$$

\section{Feedback Mode}

For measurements in FB mode, we used electrolyte solution of reduced iodide $(I)$ electrolyte as a mediator. At the UME, a potential $E_{T}$ is applied at which diffusion-controlled conversion of themediator occurs according to Equation (SI3) and thus a steady.

Diffusion-controlled reaction on the surface of sensitized nickel oxide as eq (SI 4 ) respectively.

$$
\begin{aligned}
& 3 \mathrm{I}^{-}-2 \mathrm{e}^{-} \longrightarrow \mathrm{I}_{3}^{-} \\
& \mathrm{I}_{3}^{-}+2 \mathrm{e}^{-} \longrightarrow 3 \mathrm{I}^{-}
\end{aligned}
$$

Diffusion-limited electrolysis of the $I$ mediator at the Pt UME in the bulk solution according to reaction Equation 1(a) results in a steady-state limiting current $I_{T, \infty}$ at negative potentials which is given by Equation ( $(S 5)$.

$$
I_{T, \infty}=4 n F D C r_{T}
$$

where $n$ is number of electrons transferred in reaction Equations 1(a) and 1(b), $D$ is diffusion coefficient, $C$ is concentration of electrolyte and $\mathrm{r}_{\mathrm{T}}$ is $\mathrm{UME}$ radius

\section{SI-2. Determining diffusion coefficient of $I$ in different solvent}

The voltammogram show a two sigmodal waves, corresponding to the oxidation and reduction of $I$ to $\mathrm{I}_{3}^{-}$and $\mathrm{I}_{2}^{-}$, respectively. Accordingly, it is considered that this property reduces the mobility of ions and hence the steady-state 
currents at the UME. When the steady state condition is obtained, the diffusion coefficients $D$ of $I$ in different solvent could be determined from diffusion-limited UME-currents using the following equation

$$
D=\frac{I_{T, \infty}}{4 n F\left[\mathrm{I}^{-}\right] r_{T}}
$$

Figure S1 SECM approach curves in different solvent in blue illumination
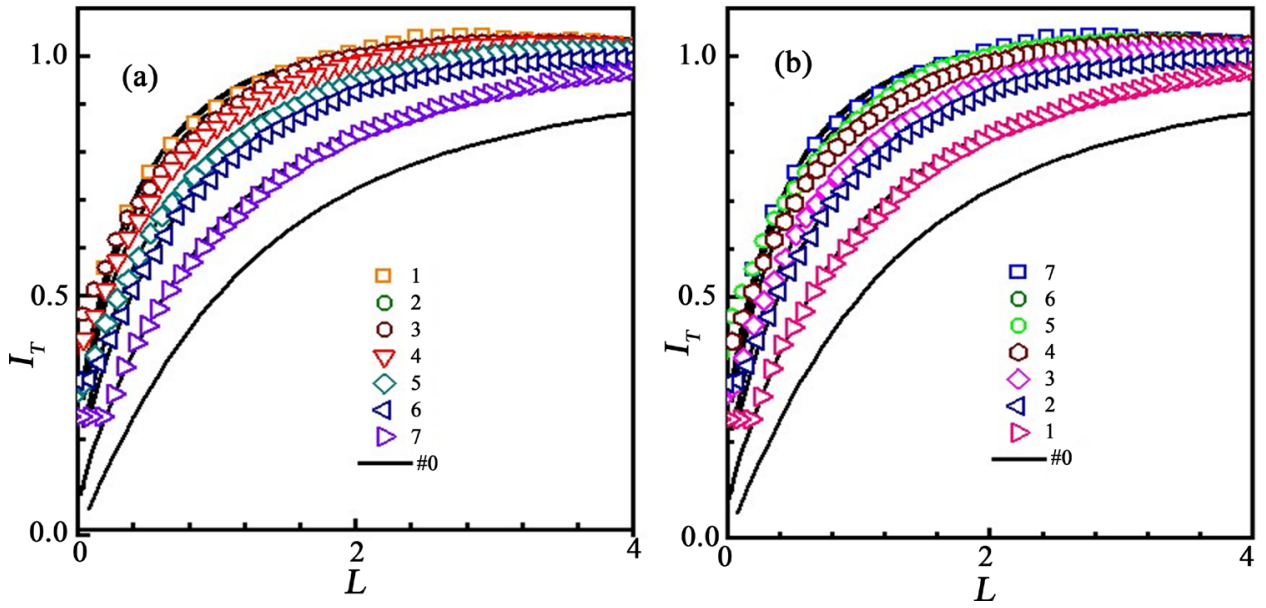

Figure S1. (a) Normalized SECM approach curves electrolyte with Pt UME $\mathrm{r}_{\mathrm{T}}=12.5 \mu \mathrm{m}$ on $\mathrm{NiO} / \mathrm{P} 1$ film under illumination with blue LED $\mathrm{J}_{\mathrm{h} v}$ Photon flux density of LED in $10^{-9} \mathrm{~mol}$ $\mathrm{cm}^{-2} \cdot \mathrm{s}^{-1}$ (1) 2.2, (2)6.1, (3) 11.8 , (4) 13.9, (5) 19.8. (6) 22.4; for $1 \mathrm{mM}(I)+0.1 \mathrm{M} \mathrm{LiClO}_{4}$, acceterional solvent with heterogeneous rate constant $\kappa$ (1) 0.0121 (2) 0.0142 (3) 0.0185 (4) 0.0242 (5) 0.0294 (6) 0.0388 and $k_{\text {eff }} \times 10^{-3} \mathrm{~cm} \cdot \mathrm{s}^{-1}$ (1) 6.29 (2) 12.3 (3) 16.6 (4) 17.6 (5) 19.6 (6) 20.21 (b). In ethanol solvent heterogeneous rate constant $\kappa$ (1) 0.098 (2) 0.111 (3) 0.145 (4) 0.179 (5) 0.223 (6) 0.243 and $k_{\text {eff }} \times 10^{-3} \mathrm{~cm} \cdot \mathrm{s}^{-1}$ (1) 1.45 (2) 1.64 (3) 2.15 (4) 2.65 (5) 3.31 (6) 3.59 (c).

\section{References}

[1] Zhang, B., Xu, X., Zhang, D., Huang, D., Li, S., Zhang, Y., Zhan, F., Deng, M., He, Y., Chen, W., Shin, Y. and Wang, M. (2014) Investigation of Dye Regeneration Kinetics in Sensitized Solar Cells by Scanning Electrochemical Microscopy. ChemPhysChem, 15, 1182-1189. https://doi.org/10.1002/cphc.201301076

[2] Alemu, G., Zhang, B.Y., Li, J.P., Xu, X.B., Cui, J., Shen, Y. and Wang, M.K. (2014) Investigation of Dye-Regeneration Kinetics at Dye-Sensitized p-Type $\mathrm{CuCrO}_{2}$ Film/Electrolytes Interface with Scanning Electrochemical Microscopy. Nano, 9, Article ID: 1440008. https://doi.org/10.1142/S1793292014400086

[3] Tefashe, U.M., Nonomura, K., Vlachopoulos, N., Hagfeldt, A. and Wittstock, G. (2012) Effect of Cation on Dye Regeneration Kinetics of N719-Sensitized $\mathrm{TiO}_{2}$ Films in Acetonitrile-Based and Ionic-Liquid-Based Electrolytes Investigated by Scanning Electrochemical Microscopy. The Journal of Physical Chemistry C, 116, 4316-4323. https://doi.org/10.1021/jp207671w

[4] Shen, Y., Nonomura, K., Schlettwein, D., Zhao, C. and Wittstock, G. (2006) Photochemical Kinetics of Eosin Y-Sensitized Zinc Oxide Films Investigated by Scanning Electrochemical Microscopy. Chemistry-A European Journal, 12, 5832-5839. https://doi.org/10.1002/chem.200501241 